\title{
High-Risk Medication Prescriptions in Primary Care for Women Without Documented Contraception
}

\author{
Bethany D. Panchal, MD, Rebecca Cash, MPH, NRP, Camille Moreno, DO, \\ Emily Vrontos, PharmD, Cheryl Bourne, CNP, Sandra Palmer, DO, \\ Amy Simpson, DO, and Ashish R. Panchal, MD, PhD
}

Introduction: During pregnancy, women may be exposed to teratogenic medications resulting in a risk of complications and poor maternal-fetal outcomes. The objective of this study was to evaluate the prescription of teratogenic medications in women of childbearing age and the associated prescription of contraception in the primary care setting.

Methods: The use of high-risk, potentially teratogenic, medications was retrospectively evaluated in women of childbearing age ( 13 to 45 years old) at 2 family medicine practices. Charts were reviewed for medication use and whether patients received a form of birth control (medication, sterilization, or postmenopausal) with the teratogenic medications. A multivariable logistic regression model was used to estimate the age-adjusted association between receiving a teratogenic medication and contraception. A subgroup analysis excluding ondansetron was also performed.

Results: A total of 3,956 nonpregnant women were included with $988(25 \%)$ prescribed at least 1 high-risk medication. The most commonly prescribed high-risk medications were ondansetron $(\mathrm{n}=$ $724,73 \%)$ and lisinopril $(n=195,20 \%)$. More than half $(55 \%)$ of the women prescribed a high-risk medication were without a form of birth control. When ondansetron was excluded, $10 \%$ of the population was prescribed at least 1 high-risk medication with $62 \%$ also without a form of birth control. Women less than 25 years of age had decreased odds of receiving contraception when prescribed a teratogenic medication (adjusted odds ratio, 0.47 ; 95\% confidence interval, $0.34-0.66$ ).

Conclusion: In a family medicine setting, $25 \%$ of women of childbearing age were prescribed a highrisk medication with over half not having evidence of contraception management. Interestingly, younger age women had lower odds of receiving contraceptive management when prescribed high-risk medications. Prescribers should be aware of and counsel on the risks of teratogenic medications and regularly evaluate reproductive plans for patients. (J Am Board Fam Med 2019;32:474-480.)

Keywords: Child Health, Community Medicine, Contraception, Counseling, Infant Health, Lisinopril, Logistic Models, Ondansetron, Pharmacoepidemiology, Primary Health Care, Preconception Care, Pregnancy, Prenatal Care, Reproductive Health, Teratogens

Prescription medication use by pregnant women has increased over the past 30 years, with best estimates demonstrating $50 \%$ of women in 2008 using at least 1 prescription medication during

This article was externally peer reviewed.

Submitted 18 September 2018; revised 3 February 2019; accepted 5 February 2019.

From Department of Family Medicine, The Ohio State University College of Medicine, Columbus, OH (BDP, EV, CB, SP, AS); Division of Epidemiology, The Ohio State University College of Public Health (RC, ARP); Department of OB/GYN and Specialized Women's Health, Cleveland Clinic Foundation, Cleveland, $\mathrm{OH}(\mathrm{CM})$; Department of Emergency Medicine, The Ohio State University College of Medicine (ARP). pregnancy. ${ }^{1-3}$ With the increased use, there has also been a concomitant increased exposure of pregnant women to medications that are potentially dangerous to the fetus, with approximately $6 \%$ of pregnant women in the United States being exposed to teratogenic medications. ${ }^{4,5}$ In 1 large retrospective analysis of pregnant patients, $4.8 \%$

Funding: none.

Conflict of interest: none declared.

Corresponding author: Bethany D. Panchal, MD, $2231 \mathrm{~N}$. High Street, Columbus, OH 43201 (E-mail: Bethany. panchal@osumc.edu). 
received a category $\mathrm{D}$ medication with an additional $4.6 \%$ a category $\mathrm{X}$ medication. ${ }^{3}$

One possible area of intervention to decrease the use of high-risk medications during pregnancy may be through better understanding the prescription practices of primary care providers (PCPs). ${ }^{6,7}$ PCPs have been noted to be responsible for the largest portion of category D or X medication prescriptions due to their regular interaction with patients with a wide variety of disease processes. ${ }^{7}$ Common medications included in this group are anxiolytics, anticonvulsants, antidepressants, antiemetics, antihypertensives, and statins and are often prescribed to women of childbearing age. ${ }^{6}$ Based on a large health care database, the use of high teratogenic risk medications were documented on 1 of every 13 ambulatory practice visits in women of childbearing age. ${ }^{6}$

Although the use of high-risk medications in women of childbearing age is sometimes necessary, the risk associated with these medications can be reduced with the provision of contraception. Unfortunately, contraception provision has been noted to be low. One study of family and internal medicine providers demonstrated low rates $(20 \%$ to $48 \%$ ) of contraception provision or counseling among females of reproductive age prescribed teratogens. ${ }^{8}$ In another evaluation, when patients have specifically been prescribed category D or X medications, only $20 \%$ of visits received contraceptive counseling. ${ }^{6}$ With these low rates of provision, it is unclear if physicians provide fertility control in patients of childbearing age who are prescribed high-risk medications. Given this knowledge gap, the objective of this study was to evaluate the use of high-risk medications in women of childbearing age and the associated use of contraception in the primary care setting at 2 clinics within an academic family medicine residency program.

\section{Methods}

\section{Study Design, Setting, and Population}

This was a retrospective evaluation of EPIC electronic medical record (EMR) data from 2 ambulatory care family medicine residency program practices associated with a large academic medical center. Nonpregnant female patients aged 13 to 45 years who were seen for at least 1 visit at the study clinics from January 1, 2015 to December 31, 2015 were included.
This study was approved by the Ohio State University Institutional Review Board, and a waiver of consent was granted.

\section{Measures}

Separate queries of the EMR system were performed to gather all nonpregnant female patients prescribed potentially teratogenic medications, taking reversible contraception, or with a history of sterilization, hysterectomy, or menopause at the 2 clinics over the study period. This information was collected from the patient's current medication list, problem list, and medical and surgical history documentation. Before data collection, small pilot evaluations were conducted to assure data extraction quality. Based on the EMR prescription records, patients were classified as receiving a highrisk medication if they were prescribed at least 1 of the following medications during the study period: simvastatin, atorvastatin, pravastatin, lisinopril, topiramate, valproic acid, ondansetron, or paroxetine. Table 1 describes these medications and their potential fetal risk in detail. These were specifically selected for inclusion based on previous studies that identified the most commonly prescribed medications in the ambulatory setting. ${ }^{6}$ Patients exposed to a high-risk medication were matched based on a unique identifier with those prescribed a form of reversible contraception (including oral contraceptive pills, intrauterine device, implant, or injectables) to determine the population at risk (patients prescribed high-risk medications without a documented form of contraception). Patients prescribed only medroxyprogesterone acetate $5 \mathrm{mg}$ or $10 \mathrm{mg}$ were considered not on contraception because this is typically only prescribed temporarily to diagnose or treat abnormal uterine bleeding. In addition, patients with a documented procedure or history of tubal ligation, hysterectomy, or menopause were classified as not at risk.

A variable was created denoting the number of different high-risk medications a patient was prescribed over the study period. Demographics collected on the entire sample included age, race, and ethnicity. Age was categorized as less than 25 years, 25 to 34 years, and 35 to 45 years based on clinical significance and approximate terciles of the overall sample. For patients taking high-risk medications, race/ethnicity was also obtained and dichotomized to white, non-Hispanic, or minority. 
Table 1. High-Risk Medications Evaluated, Pregnancy Category, and Potential Complications of Use ${ }^{16}$

\begin{tabular}{|c|c|c|c|}
\hline Medication Class & Medication Name & $\begin{array}{l}\text { Pregnancy } \\
\text { Category }\end{array}$ & $\begin{array}{c}\text { Possible Side Effects of Use during } \\
\text { Pregnancy }\end{array}$ \\
\hline $\begin{array}{l}\text { HMG-CoA reductase } \\
\text { inhibitor }\end{array}$ & $\begin{array}{l}\text { atorvastatin simvastatin } \\
\text { pravastatin }\end{array}$ & $\mathrm{X}$ & $\begin{array}{l}\text { Studies of several HMG-CoA reductase } \\
\text { inhibitors have shown congenital } \\
\text { abnormalities in infants and skeletal } \\
\text { malformations in rats and mice. }\end{array}$ \\
\hline Anticonvulsant & topiramate & X & $\begin{array}{l}\text { Increased risk for cleft lip and/or cleft } \\
\text { palate (oral cleft), hypospadias. } \\
\text { Abortions, premature births, low } \\
\text { birth weights, and a reduction in live } \\
\text { births have also been observed in } \\
\text { prospective studies. }\end{array}$ \\
\hline $\begin{array}{l}\text { Anticonvulsant/mood } \\
\text { stabilizer }\end{array}$ & valproic acid & $\mathrm{X}$ and $\mathrm{D}^{*}$ & $\begin{array}{l}\text { Valproic acid syndrome in infants } \\
\text { (facial dysmorphology, congenital } \\
\text { heart defects, spina bifida, cleft lip } \\
\text { and palate, and developmental } \\
\text { delays). }\end{array}$ \\
\hline Antiemetic & ondansetron & $\begin{array}{l}\text { Fetal risk cannot } \\
\text { be ruled out }\end{array}$ & $\begin{array}{l}\text { Inconsistent findings, possible increased } \\
\text { risk of cardiac malformations }\end{array}$ \\
\hline $\begin{array}{l}\text { Selective serotonin } \\
\text { reuptake inhibitor }\end{array}$ & paroxetine & $\begin{array}{l}\text { Fetal risk has been } \\
\text { demonstrated }\end{array}$ & $\begin{array}{l}\text { Increased risk of major congenital and } \\
\text { cardiac malformations and an } \\
\text { increased risk of pulmonary } \\
\text { hypertension of the newborn, } \\
\text { especially with use during the first } \\
\text { trimester of pregnancy. }\end{array}$ \\
\hline $\begin{array}{l}\text { Angiotensin converting } \\
\text { enzyme inhibitor }\end{array}$ & lisinopril & $\begin{array}{l}\text { Fetal risk has been } \\
\text { demonstrated }\end{array}$ & $\begin{array}{l}\text { Increased risk of spontaneous abortion, } \\
\text { oligohydramnios, and newborn renal } \\
\text { dysfunction. }\end{array}$ \\
\hline
\end{tabular}

HMG-CoA, 3-hydroxy-3-methyl-glutaryl-coenzyme A.

* $\mathrm{X}$ for migraine prophylaxis, valproate products; D for epilepsy and bipolar disorder.

\section{Analytic Approach}

The primary objective of this study was to evaluate the use of high-risk medications (simvastatin, atorvastatin, pravastatin, lisinopril, topiramate, valproic acid, ondansetron, and paroxetine) in women of childbearing age and the associated use of contraception. A subgroup analysis with the removal of ondansetron was conducted to assure that high-risk medications studied were prescribed for disease management not related to pregnancy. Ondansetron is commonly used for pregnancy-induced nausea, unlike the other medications.

All analyses were completed using STATA IC version 12.1 (StataCorp LP, College Station, TX). Descriptive statistics were calculated. $\chi^{2}$ tests and Wilcoxon rank sum test were used to evaluate comparisons between those receiving and not receiving contraception while taking a teratogenic medication. Patient age was considered a potential confounder of the association between the exposure of teratogenic medications and the outcome of having fertility controlled by contraception. Using the previously described age stratification, we used multivariable logistic regression to estimate age- adjusted odds ratios (ORs) and 95\% confidence intervals (CIs). An interaction term with age and the exposure in question were included in the model due to significance by the Wald test. All statistical analyses were performed at the $\alpha=0.05$ level.

\section{Results}

A total of 3,956 female patients were identified and included in the evaluation, with 988 (25\%) of these patients prescribed at least 1 high-risk medication on the list. When excluding ondansetron, 383 (10\%) women were prescribed at least 1 high-risk medication. Of all women prescribed a high-risk medication, $60 \%$ of women belonged to a minority group compared with the $40 \%$ who were not in a minority group (Table 2). With ondansetron excluded, the percentage changed to $57 \%$ and $43 \%$, respectively.

The most commonly prescribed high-risk medication was ondansetron $(\mathrm{n}=724,73.3 \%)$ followed by lisinopril $(\mathrm{n}=195,19.7 \%)$ and topiramate $(\mathrm{n}=$ 94, 9.5\%) (Table 2). When ondansetron was ex- 
Table 2. Demographics and Prescribed High-Risk Medications of All Women of Childbearing Age $(\mathrm{N}=988)$ and the Subgroup Excluding Ondansetron ( $\mathrm{N}=383)$

\begin{tabular}{lcc}
\hline & Patients on High-Risk Medication & High-Risk Subgroup Analysis \\
\cline { 2 - 3 } Demographic and Medication & $\mathrm{N}(\%)$ & $\mathrm{N}(\%)$ \\
\hline Age (total population) & & $30(7.8)$ \\
$\quad$ Less than 25 & $173(17.5)$ & $108(28.2)$ \\
25 to 34 & $387(39.2)$ & $245(64.0)$ \\
35 to 45 & $428(43.3)$ & $219(57.2)$ \\
Minority status & & $164(42.8)$ \\
Yes & $593(60.0)$ & $195(50.9)$ \\
No & $395(40.0)$ & $94(24.5)$ \\
High-risk medications prescribed & & $62(16.2)$ \\
Lisinopril & $195(19.7)$ & $34(8.9)$ \\
Topiramate & $94(9.5)$ & $33(8.6)$ \\
Atorvastatin & $62(6.3)$ & $27(7.1)$ \\
Paroxetin & $34(3.4)$ & $10(2.6)$ \\
Valproic acid & $33(3.3)$ & - \\
Simvastatin & $27(2.7)$ & $10(1)$ \\
Pravastatin & $724(73.3)$ & \\
Ondansetron & & \\
\hline
\end{tabular}

cluded, lisinopril accounted for 50.9\%, whereas topiramate was $24.5 \%$. Of patients prescribed a high-risk medication, $15 \%(\mathrm{n}=152)$ were prescribed more than 1 .

Contraceptive management of all women of childbearing age treated with a high-risk medication is noted in Table 3. Of the 988 women prescribed a high-risk medication, greater than half did not have contraceptive management $(\mathrm{N}=540$, $54.7 \%)$. However, patients on at least 1 high-risk medication had no significantly different odds of fertility compared with those not on a high-risk medication (unadjusted OR, 0.89; 95\% CI, 0.77$1.03 ; P=.121)$.

Analysis was also conducted after excluding ondansetron, which is often prescribed in pregnancy for nausea (Table 3). In this sample, 383 patients were prescribed a high-risk medication, excluding ondansetron. Of patients prescribed a high-risk medication, 237 (61.9\%) were found to be without a form of birth control. Patients on high-risk medications had a small but significant increase in odds of fertility compared with those not on high-risk medications (excluding ondansetron) (unadjusted OR, 1.26; 95\% CI, 1.02-1.57; $P=.034$ ).

The odds of having contraceptive management, controlling for patient age, were calculated for both populations (Table 4). Patients less than 25 years old had $53 \%$ decreased odds of receiving contraception when being prescribed a high-risk medication compared with those not prescribed 1 of these medications (adjusted OR [aOR], 0.47; 95\% CI,

Table 3. Women Childbearing Age with Contraception Management, Defined as Taking Reversible Contraception, History of Sterilization, Hysterectomy, or Menopause

\begin{tabular}{|c|c|c|}
\hline \multirow[b]{3}{*}{ Contraception } & \multirow{2}{*}{$\begin{array}{c}\frac{\text { Patients on High-Risk Medication }}{\mathrm{N}=988} \\
\end{array}$} & \multirow{2}{*}{$\frac{\text { High-Risk Medication Subgroup Analysis }}{\mathrm{N}=383}$} \\
\hline & & \\
\hline & $\mathrm{N}(\%)$ & $\mathrm{N}(\%)$ \\
\hline No contraception & $540(54.7)$ & $237(61.9)$ \\
\hline \multicolumn{3}{|l|}{ Contraception management } \\
\hline Reversible contraception & $367(37.2)$ & $115(30.0)$ \\
\hline Sterilization (tubal ligation/hysterectomy) & $27(2.7)$ & $7(1.8)$ \\
\hline Postmenopausal & $54(5.5)$ & $24(6.3)$ \\
\hline
\end{tabular}


Table 4. Odds of Having Contraceptive Management When Being Prescribed a High-Risk Medication for the Overall Study Population and Subgroup, Excluding Ondansetron, Controlling for Patient Age

\begin{tabular}{|c|c|c|c|c|}
\hline Age & High-Risk Medication Prescribed N, \% & Adjusted ORs & $95 \%$ CIs & $P$ Value \\
\hline \multicolumn{5}{|c|}{ Overall study population } \\
\hline$<25$ & 173,18 & 0.47 & 0.34 to 0.66 & $<.001$ \\
\hline 25 to 34 & 387,39 & 0.82 & 0.65 to 1.03 & .09 \\
\hline 35 to 45 & 428,43 & 1.18 & 0.93 to 1.50 & .18 \\
\hline \multicolumn{5}{|c|}{ Subgroup excluding ondansetron } \\
\hline$<25$ & 30,8 & 0.86 & 0.42 to 1.79 & .69 \\
\hline 25 to 34 & 108,28 & 0.75 & 0.50 to 1.10 & .14 \\
\hline 35 to 45 & 245,64 & 1.44 & 1.07 to 1.94 & .02 \\
\hline
\end{tabular}

CIs, confidential intervals; ORs, odd ratios.

$0.34-0.66 ; P<.001)$. For patients 35 years or older, there was an $18 \%$ increase in odds of receiving contraception when prescribed a high-risk medication compared with those not prescribed 1 of these medications, although this did not reach statistical significance (aOR, 1.18; 95\% CI, 0.93$1.50 ; P=.18)$. Further analysis in the ondansetronexcluded subgroup showed patients 35 to 45 years of age had $44 \%$ increased odds of receiving contraception when prescribed a high-risk medication other than ondansetron, compared with those not on a high-risk medication (aOR, 1.44; 95\% CI, $1.08-1.94 ; P=.02)$. This protection was not noted for the other age groups in this subgroup.

\section{Discussion}

The prevention of pregnancy complications through close monitoring of potentially teratogenic medications has been a recent focus throughout obstetric care. ${ }^{1,3-5,9}$ In this study, we demonstrated that in a family medicine setting, $25 \%$ of women of childbearing age were prescribed a high-risk medication ( $10 \%$ excluding ondansetron); over half (54.7\% and $61.9 \%$, excluding ondansetron) were also without contraception management (Table 3). Previous work by Schwarz and others ${ }^{6-8,10}$ have demonstrated the gap between the use of high-risk medications and contraception management. However, the extent of this issue in the family medicine setting is not well defined. Furthermore, the demonstration of age-based prescription practices for contraceptive management when prescribing highrisk medications is a novel finding. In our evaluation, younger aged (less than 25 years old) women had lower odds of receiving contraceptive management when prescribed 1 of these medications, whereas women with advanced maternal age had higher odds of concomitant contraception when also prescribed a high-risk medication (Table 4). Similar trends were seen in the subgroup of women excluding those with only prescriptions of ondansetron. The reason behind this practice pattern is unclear and will require further evaluation.

Multiple challenges may directly impact family physician practice patterns in regard to high-risk medications and contraceptive management. First, physicians may find it challenging to identify the pregnancy intentions of their patients, making appropriate counseling difficult. ${ }^{10}$ Second, after physicians understand a patient's reproductive plan, finding consistent and clinically relevant information on the prescribed high-risk medication may be difficult. ${ }^{9}$ There are few medications that have strict rules for prescription (ie, isotretinoin) because of the risk of teratogenicity. ${ }^{11}$ In the case of isotretinoin, rules include being aware of and documenting concomitant use of at least 2 forms of contraception to prevent pregnancy 1 month before, during, and after taking the medication. ${ }^{12,13}$ Although many other medications have been linked to fetal anatomic abnormalities; these are not monitored as strictly. The responsibility often falls to the PCP to be aware of, counsel on the risks of these potentially teratogenic medications, and regularly reevaluate reproductive plans for women at risk of pregnancy. However, primary physicians are challenged by the systems they work in where a specialist may prescribe a high-risk medication and fail to communicate with the PCP. The PCP may clinically treat that patient no more than once a year, meanwhile important reproductive plan discussions are lost in the interim. Thus, although a 
family physician may have primary responsibility of discussing reproductive plans, the interplay of the health care system and communication throughout dramatically impacts their ability to facilitate these discussions.

At the time of our study, ondansetron was being highly scrutinized due to concerns for a possible association with cardiovascular malformations. ${ }^{14}$ Although the evidence has since concluded that the risk with this medication is low, ${ }^{15}$ it seems that even during a time period of high surveillance of a certain medication, it was still highly prescribed without concomitant use of contraception. However, even with the exclusion of ondansetron, 383 (10\%) women of childbearing age were found to have been prescribed a high-risk medication, of which $268(63 \%)$ were at risk for pregnancy. This further highlights the need for improved prescribing practices for potential teratogens with appropriate counseling provided and the form of contraception documented. ${ }^{9}$ It is difficult and unfair to lay this responsibility solely at the PCP's feet, but there is an inherent responsibility nonetheless.

The primary limitations of our study were related to the data collection method and errors in documentation. Because we used an algorithm for extracting data from an EMR that may have data stored in a number of ways, it is possible that some of the information obtained was not complete. Furthermore, the information in our EMR depends on documentation from providers, including external prescriptions and surgeries. Incomplete documentation and recording by providers can lead to skewed information about current medications or previous surgeries patients may have undergone. Another limitation is that we did not account for certain other forms of contraception including condoms, abstinence, and partner sterilization. One challenge of including condom use and barrier protection in this study is that these methods are inconsistently used by patients, making their effectiveness also inconsistent. Defining these patients as "safe" from teratogens may not be appropriate. Thus, the design of this study focused on identifying the "at risk" population not using an effective form of birth control. In addition, although a patient may be prescribed a high-risk medication or contraception for that matter, it does not guarantee that she is actually taking that medication.

Nonetheless, our data set clearly demonstrated that there is a need for clarity and evidence-based guidance to improve practice patterns as well as improved communication throughout the health care continuum. Moving forward, further work will need to address the standardization of the information provided to patients on these medications as well as documentation of our recommendations for contraception if high-risk medications are prescribed.

\section{Conclusions}

In a family medicine setting, $25 \%$ of women of childbearing age were prescribed a high-risk medication, with over half $(55 \%)$ being without clear evidence of contraception management. Furthermore, younger aged (less than 25 years old) women had lower odds of receiving contraceptive management when prescribed 1 of these medications, whereas women with advanced maternal age (over 35 years old) had higher odds of concomitant contraception when also prescribed a high-risk medication. Prescribers should be aware of and counsel on the risks of medications and regularly evaluate reproductive plans for patients.

To see this article online, please go to: bttp://jabfm.org/content/ 32/4/474.full.

\section{References}

1. Mitchell AA, Gilboa SM, Werler MM, et al. Medication use during pregnancy, with particular focus on prescription drugs: 1976-2008. Am J Obstet Gynecol 2011;205:51.e1-8.

2. Egen-Lappe V, Hasford J. Drug prescription in pregnancy: analysis of a large statutory sickness fund population. Eur J Clin Pharmacol 2004;60:659-66.

3. Daw JR, Hanley GE, Greyson DL, Morgan SG. Prescription drug use during pregnancy in developed countries: a systematic review. Pharmacoepidemiol Drug Saf 2011;20:895-902.

4. Andrade SE, Gurwitz JH, Davis RL, et al. Prescription drug use in pregnancy. Am J Obstet Gynecol 2004;191:398-407.

5. Lee E, Maneno MK, Smith L, et al. National patterns of medication use during pregnancy. Pharmacoepidemiol Drug Saf 2006;15:537-45.

6. Schwarz EB, Maselli J, Norton M, Gonzales R. Prescription of teratogenic medications in United States ambulatory practices. Am J Med 2005;118:1240-9.

7. Schwarz EB, Postlethwaite DA, Hung YY, Armstrong MA. Documentation of contraception and pregnancy when prescribing potentially teratogenic medications for reproductive-age women. Ann Intern Med 2007;147:370-6.

8. Fritsche MD, Ables AZ, Bendyk H. Opportunities missed: improving the rate of contraceptive counseling or provision when prescribing reproductive-aged 
women potentially teratogenic medications in a family medicine resident clinic. Contraception 2011;84: 372-6.

9. Schwarz EB, Santucci A, Borrero S, Akers AY, Nikolajski C, Gold MA. Perspectives of primary care clinicians on teratogenic risk counseling. Birth Defects Res A Clin Mol Teratol 2009;85:858-63.

10. Pace LE, Schwarz EB. Balancing act: safe and evidence-based prescribing for women of reproductive age. Womens Health (Lond) 2012;8:415-25.

11. Garcia-Bournissen F, Tsur L, Goldstein LH, et al. Fetal exposure to isotretinoin-an international problem. Reprod Toxicol 2008;25:124-8.

12. iPledge: committed to pregnancy prevention. 2016. Available from: https://www.ipledgeprogram.com/ iPledgeUI/home.u. Accessed September 16, 2018.
13. Isotretinoin (marketed as Accutane) capsule information. United States Department of Health and $\mathrm{Hu}-$ man Services, 2007. Available from: https://www. fda.gov/Drugs/DrugSafety/ucm094305.htm. Accessed September 16, 2018.

14. Danielsson B, Wikner BN, Kallen B. Use of ondansetron during pregnancy and congenital malformations in the infant. Reprod Toxicol 2014;50: $134-7$.

15. Carstairs SD. Ondansetron use in pregnancy and birth defects: a systematic review. Obstet Gynecol 2016;127:878-83.

16. POISONDEX (Micromedex 2.0). 2018. Available from: https://www.micromedexsolutions.com/micromedex2/ librarian/. Accessed March 12, 2018. 